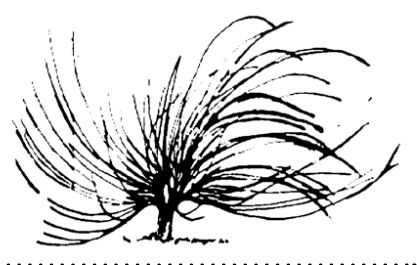

\title{
Estágio supervisionado, práticas de escrita e dispositivos de formação
}

\author{
Marinalva Vieira Barbosa ${ }^{l}$ \\ Universidade Federal do Triângulo Mineiro \\ Brasil \\ marinalvav@gmail.com \\ Juliana Bertucci Barbosa ${ }^{2}$ \\ Universidade Federal do Triângulo Mineiro \\ Brasil \\ julianabertucci@gmail.com
}

\begin{abstract}
Resumo
Neste artigo, o objetivo é apresentar um relato acerca de como são organizadas as disciplinas de Estágio Supervisionado I e II, em Língua Portuguesa, na Universidade Federal do Triângulo Mineiro (UFTM). Da perspectiva teórica, apresentamos uma articulação entre concepções vindas do campo da Educação - sobre a organização do estágio nas instituições de ensino superior -, uma concepção discursiva de linguagem baseada em Foucault (1989) e Bakhtin (1979/2003) - e uma concepção de experiência tal como proposta por Larrosa (2004). A partir dessa base teórica, assumimos que a escrita é componente fundamental à realização de uma formação que leve o futuro professor a construir conhecimentos próprios sobre a docência a partir do
\end{abstract}

http://dx.doi.org/10.15359/rep.esp-20-1.2

1 Doutora em Linguística pela Unicamp. Professora do Departamento de Linguística e Língua Portuguesa da UFTM. Pesquisadora do projeto A escrita sobre as práticas de ensino em licenciaturas do Brasil, da Costa Rica e de Honduras: registro, análise e produção de conhecimento - Chamada universal MCTI/CNPQ No 14/2014, coordenado pelo professor Thomas Fairchild.

2 Doutora em Linguística pela Unesp. Professora do Departamento de Linguística e Língua Portuguesa da UFTM. Pesquisadora do projeto A escrita sobre as práticas de ensino em licenciaturas do Brasil, da Costa Rica e de Honduras: registro, análise e produção de conhecimento - Chamada universal MCTI/CNPQ No 14/2014, coordenado pelo professor Thomas Fairchild. 
questionamento das relações possíveis (e os desafios existentes) entre teoria e prática. Trata-se, portanto, de um relato sobre a construção de dispositivos de formação - cujo eixo central é o movimento de reflexão-açãoreflexão - que permitam ao estudante de letras produzir uma escrita que seja o resultado de um conhecimento sobre o ensino da língua portuguesa.

Palavras chave: Estágio, escrita, dispositivo, formação.

\begin{abstract}
In this article, the aim is to present a report on how the subjects Supervised Internship I and II, as part of the Portuguese Literature and Language Arts course are organized at the Federal University of Triângulo Mineiro (UFTM). As a theoretical perspective, we combine conceptions derived from the field of education - on how pedagogical internship practices are organized in universities -, a discursive conception of language based on Foucault (1989) and Bakhtin (1979/2003)-, and a conception of experience as proposed by Larrosa (2004). From this theoretical basis, we assume that writing is a key component to achieving a training that leads future teachers to build their own knowledge about teaching based on the questioning of the possible relations (and existing challenges) between theory and practice. It is, therefore, a report on the construction of teacher education devices - whose central axis is the movement of reflection-action-reflection - which allows Literature and Language Arts students to write in such a way that is the result of knowledge about the teaching of the Portuguese language.
\end{abstract}

Keywords: Stage, writing, device, teacher Training

\title{
Introdução
}

Tl $\begin{aligned} & \text { o Brasil, o Estágio Supervisionado é concebido como o espaço- } \\ & \text { tempo de formação em que o futuro professor entra em contato } \\ & \text { antecipado com a situação de trabalho que será vivenciada }\end{aligned}$
após o término da formação inicial. O tempo de realização do estágio
é definido em lei - são 480 horas, incluindo preparação, observação 
e regência na escola básica. Para esse período, cada instituição de ensino superior define os conteúdos que serão ensinados. Isso gera uma infinidade de práticas e concepções de formação.

No contexto atual de formação brasileiro, de acordo com Pimenta \& Lima (2004), tem-se ao menos quatro tipos de estágios: a) centrado na observação e imitação dos professores em exercício na educação básica; b) centrado no desenvolvimento de técnicas, na universidade, para serem aplicadas em sala de aula; c) o centrado na crítica e na desvalorização de tudo o que é feito na escola; d) e o centrado na pesquisa com vistas à construção de uma relação sólida entre teoria e prática. Para Bueno (2009, p. 41-43), esses quatro tipos podem ser assim explicados:

a. o estágio centrado na observação e imitação de modelos pressupõe uma realidade que não se altera, com alunos sempre iguais vivendo em um mundo também estático, cabendo à escola ensinar-lhes a tradição. Se esses alunos não aprendem, o problema é deles, de sua família e de suas culturas, que são diferentes da ensinada e valorizada pela escola. Nele, o professor em formação deve reproduzir uma prática modelar, atendo-se à sua observação da sala de aula, desconsiderando o contexto escolar, elaborando e executando 'aulas-modelos'."

b. "o estágio centrado nas técnicas procura dar aos alunos, na universidade, os meios, as metodologias, "as receitas" que os auxiliarão nas salas de aula, discutindo e ensinado como produzir os materiais didáticos, como se portar nas salas, como falar com os alunos. Nessa visão, acredita-se que é possível ter uma técnica universal que dê conta de todas as salas, de todos os alunos de todos os lugares. Novamente, desconsidera-se o contexto sócio-histórico e cultural de cada escola, de cada nível de ensino, de cada professor".

c. [no estágio centrado na crítica à escola, aos professores e aos diretores] "o professor em formação buscaria na escola somente as falhas, os desvios, os pontos negativos, tachando os professores de ultrapassados, tradicionais e incompetentes. Somente a universidade e seus professores saberiam o que é dar aulas, ao passo que os demais estariam apenas 'enrolando'." 
d. [no estágio que alia teoria e prática por meio da pesquisa, busca-se criar as condições necessárias para que o professor em formação possa] "analisar, pensar, opinar, agir e discutir com base no que estudou, no que viu, no que praticou. Nessa perspectiva, a escola não é modelo nem lugar de aplicar técnicas prontas, nem o lado errado da educação." [O estágio nesse caso passa a ser o tempo-espaço de diálogo com a escola com vistas à construção de conhecimento sobre a docência, especificamente sobre a construção de concepções acerca do que deve ser ensinado].

A adoção de um ou mais tipos de estágios, dentre os quatro descritos, depende da concepção do professor coordenador dessa disciplina na universidade e se esta é pública ou privada. Também contribui muito para isso: a) a concepção prevalente de que a disciplina de estágio supervisionado pode ser ministrada por qualquer professor da área de conhecimento do curso, não sendo necessária formação específica para essa disciplina; b) a visão do próprio aprendiz que vê no estágio uma disciplina incômoda, deslocada de sua grade curricular normal e, portanto, que deve ser realizada nos intervalos de sua jornada de trabalho ou em períodos de férias trabalhistas; d) as concepções dos professores que supervisionam o estágio na escola que, de acordo com sua própria experiência, tendem a organizar as atividades do professor em formação dentro de um dos tipos de estágios descritos acima.

Esse conjunto de elementos contextuais, conforme já dito, faz com que a organização dessa disciplina, os conteúdos abordados e as metodologias utilizadas sejam variados no que diz respeito a sua concretização. Ou seja, a adoção de uma concepção de estágio, dentre as descritas, implica também uma concepção de formação inicial, de professor da educação básica e, principalmente, de conteúdos e objetivos a serem alcançados nessa etapa de formação do futuro professor. Diante disso, temos adotado uma concepção muito próxima à que toma o estágio como um momento de aliar teoria e prática por meio da pesquisa: Defendemos que:

O compromisso fundamental da formação de professores não é com a transmissão de um legado de saberes constituídos, mas com a formação de profissionais cujo trabalho possa somar-se a esse legado. $\mathrm{O}$ professor formado por uma universidade qualifica-se 
para participar dos processos produtivos da área profissional em que se formou, incluindo-se a produção de propostas de ensino e a pesquisa sobre os processos de ensino e aprendizagem. Sua formação deve ser suficiente para que seu trabalho não dependa exclusivamente da circulação dos produtos de pesquisas realizadas em instâncias das quais o professor não participa diretamente (como governos, mercado editorial e mesmo alguns setores da universidade). (Fairchild, 2014, p. 5)

Por essa perspectiva, a formação inicial, incluindo a etapa do estágio, será bem-sucedida se promover a formação de indivíduos que, ao dialogarem com o conhecimento teórico que lhes é dado na forma de herança cultural, produzam novos conhecimentos sobre as teorias, sobre as práticas de ensino e aprendizagem na escola básica. $\mathrm{O}$ foco central da formação volta-se, portanto, para a construção de meios para que aqueles que aprendem elaborem compreensões próprias sobre os objetos de ensino e aprendizagem. Nesse movimento, são criadas as condições para que a aprendizagem formativa do futuro professor se transforme num momento de criação e não de repetição do conhecimento já produzido em outros espaços e tempos.

\section{Escrita, pesquisa e formação: breves considerações}

A pesquisa e, consequentemente, a escrita são fundamentais à formação inicial do professor de Língua Portuguesa porque, por meio delas, torna-se possível: a) a construção de uma aprendizagem por problemas, que não é o mesmo que a formação pela prática ou a formação a partir do estudo somente da prática da sala de aula; b) a aprendizagem como consequência da mobilização de conhecimento teórico para analisar e discutir um problema e/ou um dado de interesse do professor em formação. Ou seja, o aprendizado por problemas permite a busca dos aportes teóricos e metodológicos necessários para construir respostas para suas questões e inquietações, sejam elas de ordem teórica ou ligadas à área de conhecimento em que buscar formar-se.

Nesse sentido, é importante destacar que o que está sendo nomeado como pesquisa aqui é o ato de formular uma questão-problema e trabalhar para respondê-la. A formulação do problema, nesse caso, precisa ser guiada pela mesma lógica da pesquisa para outros fins, qual seja: formular o problema, buscar a base teórica para compreendê-lo e 
construir, a partir de práticas de ensino, as reflexões e possíveis respostas, quando cabível, para o problema. Por essa perspectiva, a pesquisa é vista como um componente necessário à formação ao longo do curso e não como uma atividade extracurricular. O problema é uma situação de ensino-aprendizagem que coloca para o professor em formação uma questão que ele não pode responder sem antes fazer um percurso de estudo, reflexão e aprendizagem. É essa aprendizagem, especificamente essa experiência, que constitui o verdadeiro objetivo da proposta de pôr a pesquisa como eixo central da formação. A escrita entra como o recurso que torna possível a constituição dessa experiência e desse sujeito.

As situações-problemas caracterizam-se por recortes de um domínio complexo, cuja realização implica mobilizar recursos, tomar decisões e ativar esquemas [...]. São fragmentos relacionados com nosso trabalho, nossa interação com as pessoas, nossa realização de tarefas, nosso enfretamento de conflitos [...]. Uma situação-problema supõe considerar algo em uma certa direção ou norte. A direção confere um valor, pois convida a superar obstáculos, fazer progressos em favor do que é julgado melhor em uma dimensão lógica, social histórica, educacional, profissional, amorosa. (Macedo, 2002, pp. 114-115)

A escolha, o trabalho linguageiro exigido na elaboração e, consequentemente, na construção de respostas/reflexões para esse mesmo problema, fruto de uma inquietação própria do sujeito em formação, é um aprendizado que permite a construção de um conhecimento sobre o objeto de ensino implicado. Nesse processo, o professor em formação se vê obrigado a tomar decisões, seguir um norte, argumentar a favor ou contra a uma questão; o próprio arcabouço teórico deixa de ser um corpo inquestionável porque seus limites e contradições podem ganhar evidência na relação com os desafios existentes no contexto gerador do problema.

O pressuposto assumido é o de que a atividade de pesquisa, necessária à construção de respostas para o problema, configura-se, portanto, como uma situação criadora porque perturba, problematiza e desequilibra tanto o sujeito quanto a linguagem mobilizada. Principalmente, desestabiliza a condição de consumidor e reprodutor e textos, tão vigentes nos dias atuais. Nesse sentido, a escrita não é uma atividade que resulta do aprendizado instrumental acerca de como comunicar 
ideias com clareza e precisão, muito menos se limite ao aprendizado instrumental das regras estruturais de produção de um texto adequado à variedade padrão. A escrita pela concepção aqui defendida passa a ser o centro através do qual a formação se dá, pois obriga o sujeito a organizar no papel diversas operações discursivas que não se reduzem, e muito menos se definem, como mero domínio da estrutura da língua. Ações para compor um texto exigem que saiba argumentar com o seu tempo, que tenha conhecimentos dos saberes e valores culturais, sociais e ideológicos vigentes no contexto de produção.

Assim, escrevendo para dar materialidade ao problema e, após, para construir reflexões/respostas, o professor em formação aprende a dialogar com os discursos outros sobre a docência em língua portuguesa, sobre a escola e, sobretudo, aprende a interpretar, organizar tudo isso numa peça textual constituída e constitutiva de sua própria linguagem a respeito do objeto: o ensino-aprendizagem da leitura, da escrita ou da gramática. A escrita, por essa perspectiva, resulta do incômodo ou do susto diante da pergunta que é obrigado a fazer a si mesmo quando se depara com o problema: o que vou dizer sobre isso?

Para a construção de respostas para essa pergunta, faz-se necessário o trabalho de ler a palavra do outro para produzir a própria palavra. Isto é, ao se pôr em busca de resposta para uma questão problema, o professor em formação desenha as condições para perceber e construir os movimentos necessários de inscrição da sua própria palavra nos dizeres e discursos da cultura acadêmica, construindo, com isso, um caminho novo para si sobre as práticas e teorias necessárias ao exercício da docência.

Pela concepção exposta, a pesquisa e a escrita, de fato, são os dispositivos de formação que recobrem os demais que, no caso da disciplina de Estágio Supervisionado, são propostos como recursos para o desenvolvimento da formação. A pesquisa e, especificamente, a escrita resultante desse trabalho, permitem que o professor em formação trabalhe com a linguagem para produzir textos sobre a questão-problema. Esse trabalho o obriga a realizar gestos mínimos de interpretação dos dizeres alheios. Isso significa que, ao escrever, ele precisa aprender como se entra no jogo da linguagem-cultura, "nas doutrinas de uma formação discursiva", e deslocar-se "com relação ao senso comum, colocando algo de si naquilo que escreve"; a produção escrita exige que o professor em formação saiba "servir-se do dizer de outros que 
constituem a sua subjetividade sem que disso se aperceba necessariamente, $[. .$.$] enfim deslocar-se" para produzir seu próprio dizer sobre os$ processos de ensino-aprendizagem (Coracini, 2010, p. 36).

É importante destacar que esse processo não é simples e não se realiza de forma rápida. A inscrição inicial no universo da linguagem escrita com vistas à produção de conhecimento é, muitas vezes, incipiente, repetitiva, colada na palavra teórica. Porém, além do pressuposto assumido, de que a experiência resultante desse trabalho torna-se uma base importante para a concretização de uma formação inicial não lastreada na mera repetição da palavra alheia, a mediação do professor na universidade é fundamental. No processo de construção dessa formação que coloca a pesquisa e a escrita como dispositivos fundamentais à formação, o professor universitário precisa assumir a posição de mediador da relação entre o conhecimento existente e aquele que pode ser construído a partir do percurso formativo.

\section{Os dispositivos de formação utilizados na disciplina de estágio ${ }^{3}$}

No Brasil, geralmente, o Estágio Supervisionado é concebido como uma disciplina em que o aprendiz vai à escola para observar o contexto escolar mais amplo, a sala de aula e, após, realizar a etapa de regência - momento em que assume a posição professor, sob a supervisão do docente que o acolheu como professor em formação, para planejar atividades de ensino, ministrar aulas. Conforme já dito, esse eixo mais comum, quando se trata do registro escrito sobre a sua concretização, sofre variações resultantes da característica da instituição de ensino superior (pública ou privada) e das concepções de estágio, ensino, escola e linguagem adotadas pelo professor que ministra a disciplina. Consequentemente, têm-se registros escritos na forma de diários de campo, relatórios, portfólios, projetos, seminários, dentre outros.

$\mathrm{Na}$ UFTM, nos estágios de Língua Portuguesa, adotamos os seguintes dispositivos de formação: o diário de campo, projeto, relatório

3 A noção de dispositivo de formação está ancorada na ideia de dispositivo, conforme descrito por Foucault (1989), como: [...] um conjunto decididamente heterogêneo que engloba discursos, instituições, organizações arquitetônicas, decisões regulamentares, leis, medidas administrativas, enunciados científicos, proposições filosóficas, morais, filantrópicas. Em suma, o dito e o não dito são os elementos do dispositivo. O dispositivo é a rede que se pode estabelecer entre estes elementos (Foucault, 1989, p. 244). Neste caso, dispositivo de formação são as estratégias usadas com o objetivo de provocar aprendizagens a partir de formas específicas de relação (e organização) com a linguagem e o conhecimento. 
e seminário, que são mobilizados de forma sequenciada e complementar ao longo da disciplina. O diário de campo é o recurso inicial de registros imediatos da rotina e observações do contexto escolar. Por se tratar de um registro primário (que deve conter os dados necessários para fundamentar a elaboração do projeto e relatório), o professor em formação é orientado sobre as possibilidades de organização escrita do diário com base na metodologia de realização de "notas substantivas", "notas metodológicas" ou "notas analíticas" (Queiroz \& Rodrigues, 2002) 4 . Também é orientando sobre a necessidade de ter um problema - relacionado ao ensino-aprendizagem da leitura, escrita ou gramática - que deverá ser discutido teoricamente e trabalhado durante o estágio, especificamente no momento da regência - concebida como momento de intervenção.

Nesse sentido, inicialmente, o diário de campo funciona como um recurso que permite os registros de informações e também é um primeiro exercício de escrita guiado pelas seguintes orientações: descrever os sujeitos, os espaços físicos e simbólicos da escola e registrar os primeiros sentidos que produzem para o professor em formação. $\mathrm{O}$ uso do diário permanece em todas as etapas do estágio; o que muda são o foco e os objetos dos registros. Por exemplo, na etapa de observação das aulas do professor supervisor do estágio, o foco recai sobre as metodologias de ensino, as formas de aprendizagens, as interações professor-aluno e aluno-aluno; na regência, o próprio professor em formação, os resultados das suas práticas de ensino, os retornos dos alunos passam a ser o objeto de registro no diário de campo.

Após o início do estágio e antes da elaboração do projeto, o professor em formação, além de fazer os primeiros registros escritos sobre

4 Os diários substantivos ou diários de observação visam precisamente reconstituir uma descrição da organização social e cultural, com o objetivo de caracterizar situações, atores e comportamentos. Os diários analíticos - ou diários teóricos condensam reflexões ou comentários acerca do modo como, ao longo da investigação, se processam e desenvolvem as relações entre teoria e empiria. Funcionam igualmente como repositório de linhas de perspectiva teórica a aprofundar e como meio de controle das hipóteses de partida. Os diários metodológicos, por seu turno, visam responder a duas preocupações essenciais de qualquer investigador: por um lado, reproduzem reflexões sobre a heuristicidade e adequação epistemológica das técnicas mobilizadas ao longo do processo de pesquisa empírica, contribuindo igualmente para o esforço de autoanálise que a reflexão sobre o nosso próprio papel e posicionamento enquanto investigadores constitui; por outro lado, permitem alinhavar caminhos metodológicos alternativos e perspectivar a mobilização de técnicas não previstas no dispositivo de pesquisa inicialmente programado (Queiroz \& Rodrigues, 2002, pp. 110-120). 
a escola, também é orientando a fazer leituras de uma bibliografia básica da área de Linguística e Ensino de Língua Portuguesa para fundamentar as análises que fará do material recolhido durante a etapa de observação da prática do professor supervisor e também a concepção, planejamento e desenvolvimento da regência. As teorias indicadas têm como eixo o seguinte: Leitura $\leftrightarrow$ produção escrita $\leftrightarrow$ análise linguística $\leftrightarrow$ diagnóstico $\leftrightarrow$ reescrita. Por essa perspectiva, a proposta de intervenção priorizará o uso (leitura e escrita) e reflexão (reescrita) da língua.

O segundo dispositivo de formação utilizado é o projeto. Este é elaborado após a realização da etapa de observação das aulas do professor supervisor do estágio e deve ter como foco a concepção, planejamento e desenvolvimento da etapa de regência. Portanto, o projeto deve conter uma proposta de intervenção e é semelhante ao projeto de pesquisa que comumente é elaborado na universidade. Por isso, contém a seguinte estrutura: introdução, fundamentação teórica e metodologia. A diferença está na organização do conteúdo de cada um desses tópicos, uma vez que no projeto de intervenção o professor em formação deve: a) na introdução apresentar o problema de ensino observado em sala de aula e, com base nisso, justificar o foco da proposta de intervenção: se a leitura, a escrita ou a gramática; b) na fundamentação teórica deve discutir as teorias de apoio e, principalmente, apontar como embasaram a formulação do problema e também como sustentarão a construção da proposta de intervenção; c) na metodologia, deve apresentar o plano para um conjunto de aulas com vistas à abordagem do problema. Especificamente, deve apresentar as estratégias de ensino que lançará mão em cada aula da etapa de regência.

O terceiro dispositivo de formação utilizado na disciplina de Estágio Supervisionado em Língua Portuguesa é o relatório - que está dividido em duas etapas (parcial e final). Após o início da regência, o professor em formação segue usando o diário de campo como recurso para registro da sua prática e observações. Como já dito, o diário também é um recurso fundamental para coleta dos dados necessários a realização do relatório. Na produção do relatório, a orientação é para que o professor em formação descreva e analise cada uma das etapas do estágio: a) o contexto escolar mais amplo (a escola e suas formas de organização, estrutura física e humana e contexto social em que está inserida); b) a sala de aula do professor supervisor, especificamente as interações, as metodologias de ensino e as aprendizagens; c) a regência 
(a realização, os resultados e os percalços). Por isso, o relatório de estágio precisa apresentar uma descrição e reflexão sobre os fatos observados e as atividades desenvolvidas, seguidas de uma análise crítica e conclusiva. Tudo que o professor em formação vivenciou durante o estágio deve ser analisado de forma criteriosa, de forma que, além de relatar sua experiência, demonstre o conhecimento adquirido durante a graduação, traçando conclusões a partir das teorias estudadas para a disciplina e/ou ao longo do curso.

Por fim, para finalizar a disciplina, ocorre a realização do Colóquio de Estágio Supervisionado em Letras, que tem como objetivo ser um momento em que os estágios das disciplinas I e II se reúnem para apresentar os resultados e as reflexões sobre o estágio. Esse evento é organizado pelos estagiários e é composto por sessões de comunicação e debate e, para encerrar, uma mesa-redonda (geralmente, composta por professores da UFTM, professores supervisores do estágio e um aluno professor em formação). Em todos os momentos desse colóquio, a meta é criar condições para que os envolvidos possam apresentar suas concepções e interpretações sobre a experiência vivenciada. Mas não só: o ato de organizar o evento coloca também o desafio da tomada de decisão, do planejamento - um aprendizado necessário ao professor.

\section{Escrita, recusa à imobilidade e construção de experiência}

Para finalizar este artigo, é importante destacar que diário de campo, projeto, relatório e colóquio não são dispositivos novos, portanto não estão sendo aqui apresentados como recursos de formação inovadores e que terão poder de mudar magicamente a relação do futuro professor com o conhecimento. De fato, estão sendo mobilizados de forma sequenciada e complementar porque, para ganhar materialidade, exigem trabalho com e na linguagem escrita. Essa é a estratégia central que norteia todo o trabalho desenvolvido no interior da disciplina Estágio Supervisionado em Língua Portuguesa - a produção de uma escrita como forma de recusa à imobilidade e à reprodução da palavra alheia sobre o fazer e as compreensões sobre a escola; também como meio de (re)criação de si mesmo a partir do diálogo com outro materializado na forma de conhecimento teórico ou sujeitos fisicamente existentes nos espaços da escola e da universidade. Nesse sentido: 
A importância da escrita, sobretudo da escrita singular, apoiase na visão de que um trabalho criativo resiste à imposição de modelos, à fetichização de autores e à homogeneização imposta pelas regras de uma ordem do discurso (Foucault 1979) que busca a estabilização dessas mesmas regras para a veiculação de um discurso 'verdadeiro'. (Carmagnani, 2010, p. 67)

A construção dessa escrita singular exige mediação e/ou diálogo com o outro. Exige o gesto autônomo de buscar, pesquisar para construir respostas. Diante disso, a reescrita (trabalhada a partir da leitura do coordenador do estágio) é uma etapa fundamental nesse trabalho. Os professores em formação são impulsionados conceber a reescrita não só como estratégia de ensino para a escola. Na universidade, na disciplina de estágio, na elaboração de cada um desses dispositivos, eles são levados a reescrever os seus textos. As produções escritas são, portanto, espaços para questionamentos sobre as construções linguísticas, sobre os limites e alcances das teorias adotadas para responder ao problema formulado, sobre as interpretações feitas acerca da escola e, principalmente, sobre concepções, muitas vezes, estabilizadas, petrificadas que o professor em formação traz consigo sobre o ato de ensinar a língua portuguesa, a leitura e a escrita.

Nesse sentido, a proposta para que a escrita seja o dispositivo principal de formação está alicerçada na concepção de que é necessária ao futuro professor a experiência do pensar próprio sobre o ensino e aprendizagem da língua portuguesa. Experiência essa que, acreditamos, é construída a partir do trabalho realizado ao longo do estágio, tal como descrito anteriormente. De acordo com Larrosa (2004), "costuma-se pensar a educação do ponto de vista da relação entre a ciência e a técnica ou, às vezes, do ponto de vista da relação entre teoria e prática". Para o autor, "somente nesta última perspectiva tem sentido a palavra 'reflexão' e expressões como 'reflexão crítica', 'reflexão sobre a prática ou na prática', 'reflexão emancipadora', etc.” (Larrosa, 2004). No entanto, segundo o autor, é possível pensar a educação a partir do par experiência e sentido.

A hipótese assumida, ao propormos um percurso de formação lastreado na escrita, é a de que o gesto de escrever, refletir, reescrever sobre o vivido na escola durante o estágio pode possibilitar a construção dessa experiência e sentido, uma vez que, na concepção de educação 
defendida por Larrosa, a experiência produz deslocamentos na instrumentalização do conhecimento porque é algo que se passa com o sujeito enquanto um saber propiciado pelo acontecimento do vivido. Trata-se de uma experiência que se traduz em um modo de estar no mundo e de olhar e compreender o mundo - neste caso, a escola e a docência.

A alteridade e o acontecimento são princípios fundamentais dessa concepção de experiência, tanto que Larrosa (2004) explica que é o se passa com o sujeito - mas que com ele não se confunde - que permite a sua constituição. Não há, portanto, experiência sem a participação do outro, sem a alteridade. É isso que nos permite conceber a formação a partir de uma relação entre teoria e prática que coloca o professor em formação como centro de construção desse diálogo a partir de uma escrita que busca construir compreensões e respostas para uma questão que o incomoda.

Por essa perspectiva, a experiência resultante do trabalho de construir respostas para questões que são próprias ao sujeito se configura como o lugar mesmo de transformação de conhecimentos teóricos; é práxis. $\mathrm{O}$ trabalho com a linguagem para construir essas respostas permite que, entre teoria e prática, abra-se um espaço para atuação desse professor em formação que, imbuído de responder a uma pergunta que o incomoda, não somente toma conhecimento da existência da teoria e/ou dos problemas relacionados à escola. Também, nesse espaço, o seu trabalho em busca de uma resposta para a questão problema não se confunde com o mero lugar do experimento, da pura apropriação e transposição de teorias para o contexto da sala de aula. Nessa perspectiva, a teoria deixa de ser um objeto estranho, indicado para resolver um problema também não conhecido, estranho. Ela passa a ser um recurso que permite ao professor em formação posicionar-se, olhar, compreender e construir uma resposta para si. Esse movimento define então uma forma de apropriação das teorias que é da ordem da implicação, da necessidade e do desejo.

\section{Referências}

Bakhtin, M. (1979) (2003). Estética da criação Verbal. Trad. Paulo Bezerra. São Paulo: Martins Fontes.

Bueno, L. (2009). A construção de representações sobre o trabalho docente: o papel do estágio. São Paulo: Fapesp/Educ. 
Carmagnani, A. M. (2010). A escrita como recusa da imobilidade: o autor e a política da criação de si. In: Coracini, M. J. R. Discurso e escrit(ur)a: entre a necessidade e a (im)possibilidade de ensinar. Campinas: Mercado de Letras.

Coracini, M. J. R. (2010). Discurso e escrit(ur)a: entre a necessidade e a (im)possibilidade de ensinar. In: Eckert-Hoff, B. M.; Coracini, M. J. R. F. Escrit(ur)a de si e alteridade no espaço papel-tela. Campinas: Mercado de Letras.

Fairchild, T. M (et.all.). (2014). A escrita sobre as práticas de ensino em licenciaturas do Brasil, da Costa Rica e de Honduras: registro, análise e produção de conhecimento. Projeto de pesquisa em andamento. Universidade Federal do Pará.

Foucault, M. (1989). Microfisica do poder. Rio de Janeiro: Graal.

Larrosa, J. (2004). Linguagem e educação depois de babel. Belo Horizonte: Autêntica.

Macedo, L. (2002) Situação-problema: Forma e Recurso de Avaliação, Desenvolvimento de Competências e Aprendizagem Escolar. In: Perrenoud, P. et. Al. As competências para ensinar no século XXI: a formação dos professores e o desafio da avaliação. Porto Alegre: Artmed.

Perrenoud, P. et. Al. (2002). As competências para ensinar no século XXI: a formação dos professores e o desafio da avaliação. Porto Alegre: Artmed.

Pimenta, S. G; Lima, M. S. L. (2004). Estágio e docência. São Paulo: Cortez.

Queiroz, J.; Rodrigues, V. Uma introdução à utilização do diário de campo e da fotografia na pesquisa sociológica. Recuperado a 25 de dezembro de 2015, em http://www.isociologia.pt/App_Files/ Documents/working14_101019094320.pdf 